\title{
ANALISIS LAJU PERPINDAHAN PANAS MENYELURUH PADA RADIATOR MOTOR ORIGINAL EQUIEPMENT MANUFACTURE (OEM) TERHADAP RACING
}

\author{
Yafid Effendi, Muhammad Safiq \\ Program Studi Teknik mesin, Fakultas teknik, Universitas Muhammadiyah Tangerang, \\ Jl. Perintis Kemerdekaan I, No.33, Cikokol, Tangerang, Banten 15118, Indonesia \\ Email: yafid_effendi@yahoo.com dan safiq.jmsd17@gmail.com
}

\begin{abstract}
ABSTRAK
Tujuan penelitian ini adalah menganalisis laju perpindahan panas $(Q)$ pada radiator OEM (Original Eqiuepment Manufacture) dan radiator Racing. Spesifikasi radiator Racing : fin pitch 2,5 mm, tube pitch $8,5 \mathrm{~mm}$, tube / row $x$ row $(19 \times 1) \mathrm{mm}$, sedangkan pada radiator $O E M$ : fin pitch 2,5 $\mathrm{mm}$, tube pitch 10 $\mathrm{mm}$, tube / row $x$ row $(12 \times 1) \mathrm{mm}$. Radiator adalah alat penukar panas yang digunakan untuk memindahkan energi panas dari satu medium ke medium lainnya yang tujuannya untuk mendinginkan maupun memanaskan. Jenis aliran radiator dibedakan menjadi 2 yaitu Down Water Flow Radiator dan Cross Water Flow Radiator. Elemen-elemen radiator seperti Tube, Tanki, Filler Neck, Fin, Pipa, Heade plate, Side Plate. Kesimpulan yang diperoleh dari perhitungan heat exchanger (Radiator) yang terpenting adalah luas dari pada sarang core tingi $\mathrm{x}$ lebar $\mathrm{x}$ tebal $=\mathrm{H} \times \mathrm{W} \times \mathrm{T}$ mm yaitu core pada radiator Racing (200 x $168 \times 23) \mathrm{mm}$ dengan total luas permukaan core $(A) \mathbf{1 , 1 4 0} \mathbf{m}^{2}$ maka laju perpindahan kalor menyeluruh $(Q)$ yang terjadi sebesar 2821 Watt, sedangkan core pada radiator Original Equiepment Manufacture $(O E M)(198 \times 128 \times 24) \mathrm{mm}$ dengan total luas permukaan core $(A) \mathbf{0 , 9 1 3} \mathbf{~ m}^{2}$ maka laju perpindahan kalor menyeluruh $(Q)$ yang terjadi sebesar 2259 Watt dengan Gap 562 Watt. Penuruna suhu water $(\triangle \mathrm{T}$ Water $)$ yang terjadi pada radiator Racing sebesar $0,58^{\circ} \mathrm{C}$ serta pada radiator $O E M$ sebesar $0,46{ }^{\circ} \mathrm{C}$ maka Gap yang diperoleh dari perbandingan adalah $0,12^{\circ} \mathrm{C}$.
\end{abstract}

Kata kunci : Analisis, Perpindahan Panas, Radiator, Motor. 


\section{Pendahuluan}

Kinerja mesin kendaraan selalu menghasilkan getaran dan panas, tidak ada satu pun mesin kenadaraan yang berkerja dengan efisien yang sempurna (tidak ada getaran maupun panas). Masalah getaran dapat diredam Shock Absorber mau pun dapat diredam dengan bantalan sedangkan untuk masalah Overheat dapat di atasi dengan menggunakan Radiator. Mesin selalu dikembangkan untuk mencapai efisiensi tertinggi, tetapi juga mempertimbangkan faktor ekonomis, daya tahan, keselamatan serta ramah lingkungan. Sistem pendinginan digunakan agar temperatur mesin terjaga pada batas temperatur kerja yang ideal. Prinsip pendinginan adalah melepaskan panas mesin ke udara, tipe langsung dilepaskan ke udara disebut pendinginan udara (air cooling), tipe menggunakan fluida sebagai perantara disebut pendinginan air, sumber (https://id.wikipedia.org/wiki/Sistem_ pendinginan).

Radiator adalah alat penukar panas yang digunakan untuk memindahkan energi panas dari satu medium ke medium lainnya yang tujuannya untuk mendinginkan maupun memanaskan. Radiator yang kita kenal pada umumnya digunakan pada kendaraan bermotor (roda dua atau roda empat), namun tidak jarang radiator juga digunakan pada mesin yang memerlukan pendinginan ekstra. Seperti pada mesin mesin produksi atau mesin mesin lainnya yang bekerja dalam kondisi kerja berat atau lama, sumber (https://id.wikipedia.org/wiki/Radiator). Proses kerja suatu motor bakar, panas yang dihasilkan perpengaruh terhadap effiensi mesin. Suhu optimal dari panas yang dihasilkan oleh suatu motor bakar pada kendaraan adalah $80-90^{\circ} \mathrm{C}$. Suhu ini sering disebut sebagai suhu kerja dari motor bakar tersebut. Fungsi dari radiator inilah yang menjaga agar panas yang dihasilkan oleh mesin ini tetap setabil. Melalaui aliran fluida pada radiator dan aliran udara, sehingga panas yang dihasilkan oleh mesin tersebut dapat diredam pada suhu optimal, sumber (Daryanto, 1992).

\section{Metodologi Penelitian}

a. Design Radiator Motor Racing

Detail spesifikasi dari design radiator motor Racing bisa dilihat pada Gambar 1 dan Tabel 1 di bawah ini.

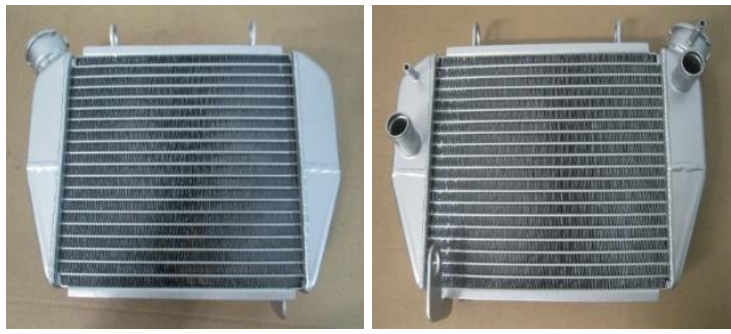

Gambar 1 Radiator Motor Racing (tampak depan dan belakang)

Tabel 1 Radiator Racing Specification

\begin{tabular}{|l|l|}
\hline Description & $\begin{array}{l}\text { Radiator } \\
\text { Racing }\end{array}$ \\
\hline Type & CT 85 \\
\hline Maker & Indonesia \\
\hline Core $($ HxWxTHK) & $200 \times 168 \times 23$ \\
\hline Tube/RowxRow & $19 \times 1$ \\
\hline Size of Tube $($ Wx H) & $22 \times 2,0$ \\
\hline Pitch TPxFTP & $8,5 \times 2,5$ \\
\hline Block Material & Alumunium \\
\hline
\end{tabular}

b. Design Radiator Motor Original Equiepment Manufacture (OEM)

Detail spesifikasi dari design radiator $O E M$ bisa dilihat pada Gambar 2 dan Tabel 2 di bawah ini.
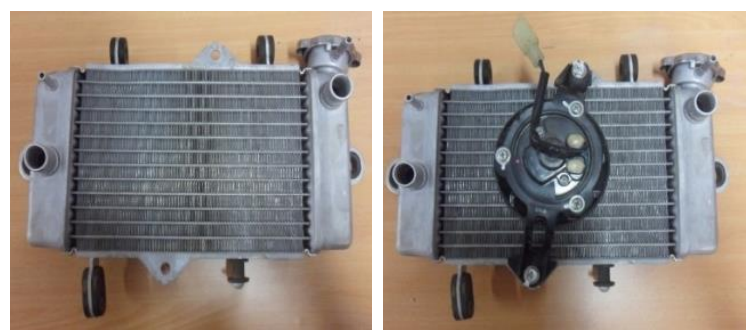

Gambar 2 Radiator $O E M$ (tampak depan dan belakang) 
Tabel 2 Radiator OEM Specification

\begin{tabular}{|l|l|}
\hline Description & Radiator OEM \\
\hline Type & CT 100 \\
\hline Maker & TSI \\
\hline Core $($ HxWxTHK $)$ & $198 \times 128 \times 24$ \\
\hline Tube/RowxRow & $12 \times 1$ \\
\hline Size of Tube $(W \times H)$ & $24 \times 2,0$ \\
\hline Pitch TPxFTP & $10 \times 2,5$ \\
\hline Block Material & Alumunium \\
\hline
\end{tabular}

Prosedur pengujian dapat dilakukan dengan beberapa tahap antara lain :

1. Pengukuran dimensi Tube dan Fin pada radiator.

2. Pengumpulan sumber data primer dan sekunder seperti :

a. Overall heat transfer (Koefisien perpindahan kalor menyeluruh)

b. Mass flow rate (laju aliran masa)

c. Specific Heat Capacity pada temperature water (Kemampuan suatu material menyerap panas)

d. $T$ in water (Suhu air panas yang masuk ke radiator)

e. T out air (Suhu udara yang dihermbuskan ke radiator)

3. Perhitungan menggunakan rumus empiris Laju Perpindahan Kalor Menyeluruh $(Q)$ baik konveksi dan konduksi.

\section{Analisa dan Pembahasan}

Pengumpulan data yang digunakan untuk menghitung design Radiator Motor Original Equiepment Manufacture (OEM) dan Racing ada beberapa data yang digunakan sebagai berikut :

\section{1.a.1 Overall Heat Transfer atau Koefisien Perpindahan Kalor Menyeluruh $\left(Q=W / m^{2} K\right)$}

a. Jika material yang di gunakan untuk alat penukar kalor yang mengunakan jenis material berbahan Copper/Brass - water maka $50 \mathrm{~W} / \mathrm{m}^{2} \mathrm{~K}$.

b. Jika material yang di gunakan untuk alat penukar kalor yang mengunakan jenis material berbahan Aluminium-water maka $45 \mathrm{~W} / \mathrm{m}^{2} \mathrm{~K}$.

Nilai overall heat transfer yang didapat dari Tabel 1.3 Koefisien perpindahan kalor menyeluruh.

\section{1.a.2 Mass Flow Rate $(\mathrm{kg} / \mathrm{s})$}

Nilai Mass Flow Rate $(\mathrm{kg} / \mathrm{s})$ kita dapatkan dari data sheet engine pada Cooling system yaitu Coolant Flow to Engine Heat Exchanger adalah 70 $l / \min$ dikonversikan dari $l / \min$ ke $\mathrm{kg} / \mathrm{s}$.

$\dot{m}=\dot{V} x \rho$

$\dot{m}=$ Masa $(\mathrm{kg} / \mathrm{s})$

$\dot{V}=$ Volume $(l)$

$\rho=$ Masa jenis $(\mathrm{kg} / \mathrm{l})$

$=70 \mathrm{l} \times 1 \mathrm{~kg} / \mathrm{l}$

$=70 \mathbf{~} g$

Diketahui :

$1 \mathrm{~min}=60 \mathrm{sec}$

Sehingga :

$$
70 \mathrm{l} / \mathrm{min}=\frac{70 \mathrm{~kg}}{60 \mathrm{~s}}=\mathbf{1 . 1 6} \mathrm{kg} / \mathrm{s}
$$

Maka $70 \mathrm{l} / \mathrm{min}$ di konversikan $(\mathrm{kg} / \mathrm{s})$ adalah menjadi $1.16 \mathrm{~kg} / \mathrm{s}$.

\section{1.a.3 Inlet Temperature $\left({ }^{\circ} \mathrm{C}\right)$}

a. Hot side.

Nilai Inlet Temperature $\left({ }^{\circ} \mathrm{C}\right)$ kita dapatkan dari data sheet engine pada Cooling system yaitu Standard Thermostat Operating Range (Full Open) adalah $90{ }^{\circ} \mathrm{C}$.

b. Cold side

Cold side adalah udara yang dihembuskan oleh angin yang melewati core $35^{\circ} \mathrm{C}$.

\section{1.a.4 Specific Heat Capacity $(\mathrm{J} / \mathrm{kg} \mathrm{K})$}

Heat Capacity ialah suatu material akan meningkat temperaturnya apabila dipanaskan dengan menyerap sejumlah energi. Sifat tersebut dinamaka heat capacity yaitu kemampuan suatu material untuk menyerap panas dari lingkungan dengan menyerap sejumlah energi untuk menghasikan kenaikan suhu sebesar 1 derajat.

a. Water

Nilai Specifc Heat Capacity diperoleh dari nilai inlet temperature. Dari tabel dibawah 
dapat dilihat nilai Specifc Heat Capacity pada temperature water $90{ }^{\circ} \mathrm{C}$ adalah.

Tabel 3 Physical Properties of Saturated Water

\begin{tabular}{|c|c|c|c|c|c|c|c|c|}
\hline \multirow{2}{*}{$\begin{array}{l}\text { Temp. } \\
T,{ }^{\circ} \mathrm{C} \\
\end{array}$} & \multirow{2}{*}{$\begin{array}{c}\text { Saturation } \\
\text { Pressure } \\
P_{\text {sst }}, \mathrm{kPa}\end{array}$} & \multicolumn{2}{|c|}{$\begin{array}{l}\text { Density } \\
\rho, \mathrm{kg} / \mathrm{m}^{3}\end{array}$} & \multirow{2}{*}{$\begin{array}{c}\text { Enthalpy } \\
\text { of } \\
\text { Vaporization } \\
h_{\mathrm{gg}}, \mathrm{kJ} / \mathrm{kg}\end{array}$} & \multicolumn{2}{|c|}{$\begin{array}{c}\text { Specific } \\
\text { Heat } \\
c_{p}, \mathrm{~J} / \mathrm{kg} \cdot \mathrm{K} \\
\end{array}$} & \multicolumn{2}{|c|}{$\begin{array}{c}\text { Thermal } \\
\text { Conductivity } \\
\mathrm{k}, \mathrm{W} / \mathrm{m} \cdot \mathrm{K}\end{array}$} \\
\hline & & Liquid & Vapor & & Liquid & Vapor & Liquid & Vapor \\
\hline 0.01 & 0.6113 & 999.8 & 0.0048 & 2501 & 4217 & 1854 & 0.561 & 0.0171 \\
\hline 5 & 0.8721 & 999.9 & 0.0068 & 2490 & 4205 & 1857 & 0.571 & 0.0173 \\
\hline 10 & 1.2276 & 999.7 & 0.0094 & 2478 & 4194 & 1862 & 0.580 & 0.0176 \\
\hline 15 & 1.7051 & 999.1 & 0.0128 & 2466 & 4185 & 1863 & 0.589 & 0.0179 \\
\hline 20 & 2.339 & 998.0 & 0.0173 & 2454 & 4182 & 1867 & 0.598 & 0.0182 \\
\hline 25 & 3.169 & 997.0 & 0.0231 & 2442 & 4180 & 1870 & 0.607 & 0.0186 \\
\hline 30 & 4.246 & 996.0 & 0.0304 & 2431 & 4178 & 1875 & 0.615 & 0.0189 \\
\hline 35 & 5.628 & 994.0 & 0.0397 & 2419 & 4178 & 1880 & 0.623 & 0.0192 \\
\hline 40 & 7.384 & 992.1 & 0.0512 & 2407 & 4179 & 1885 & 0.631 & 0.0196 \\
\hline 45 & 9.593 & 990.1 & 0.0655 & 2395 & 4180 & 1892 & 0.637 & 0.0200 \\
\hline 50 & 12.35 & 988.1 & 0.0831 & 2383 & 4181 & 1900 & 0.644 & 0.0204 \\
\hline 55 & 15.76 & 985.2 & 0.1045 & 2371 & 4183 & 1908 & 0.649 & 0.0208 \\
\hline 60 & 19.94 & 983.3 & 0.1304 & 2359 & 4185 & 1916 & 0.654 & 0.0212 \\
\hline 65 & 25.03 & 980.4 & 0.1614 & 2346 & 4187 & 1926 & 0.659 & 0.0216 \\
\hline 70 & 31.19 & 977.5 & 0.1983 & 2334 & 4190 & 1936 & 0.663 & 0.0221 \\
\hline 75 & 38.58 & 974.7 & 0.2421 & 2321 & 4193 & 1948 & 0.667 & 0.0225 \\
\hline 80 & 47.39 & 971.8 & 0.2935 & 2309 & 4197 & 1962 & 0.670 & 0.0230 \\
\hline 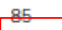 & 57.83 & 968.1 & 0.3536 & 2296 & 4201 & 1977 & 0.673 & 0.0235 \\
\hline 90 & 70.14 & 965.3 & 0.4235 & 2283 & 4206 & D1993 & 0.675 & 0.0240 \\
\hline 3 & 84.55 & 961.5 & 0.5045 & 2270 & & $J_{2010}$ & 0.677 & \\
\hline 100 & 101.33 & 957.9 & 0.5978 & 2257 & 4217 & 2029 & 0.679 & 0.0251 \\
\hline
\end{tabular}

b. Air

Nilai Specifc Heat Capacity diperoleh dari nilai ambient. Dari tabel dibawah dapat dilihat nilai Specifc Heat Capacity pada temperature air $35^{\circ} \mathrm{C}$ adalah.

Tabel 4 Physical Properties of Saturated Air

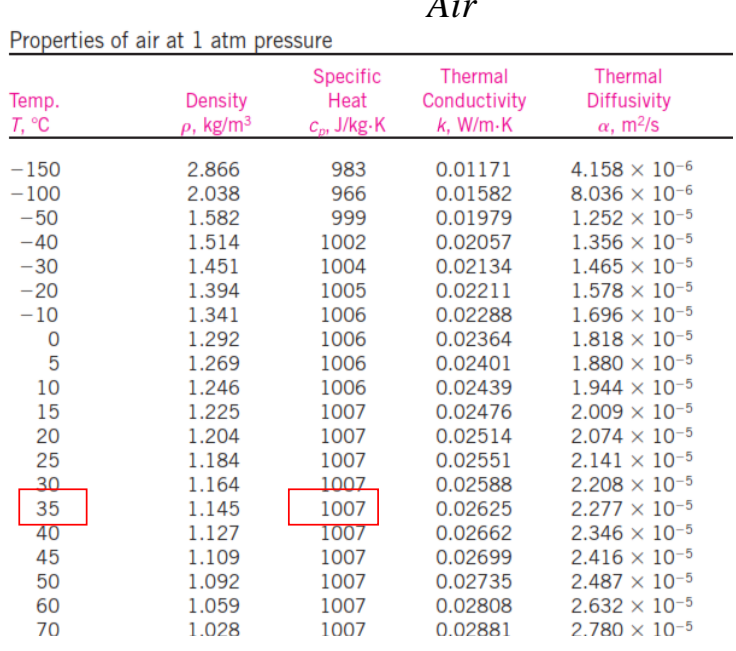

Design Delta Temperature $\left({ }^{\circ} \mathrm{C}\right)$ untuk nilai design delta temperature Standart adalah 10, 15, 20, 25

\section{a. Analisa Radiator Racing}

Ukuran core radiator adalah adalah tinggi $\mathrm{x}$ lebar $\mathrm{x}$ tebal $=\mathrm{H} \times \mathrm{W} \times \mathrm{T} \mathrm{mm}$. Untuk jenis yang digunakan adalah $(200 \times 168 \times 23) \mathrm{mm}$.

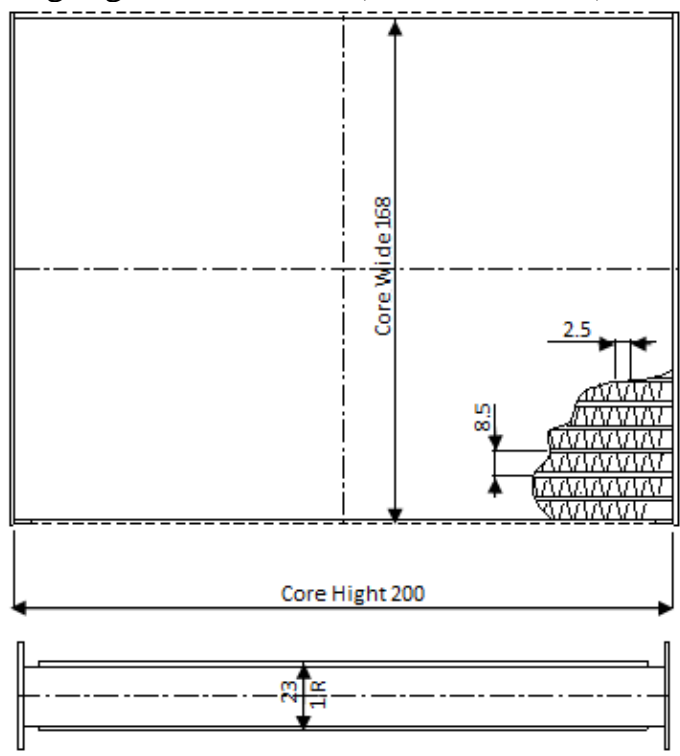

Gambar 3 Dimensi Core Racing

1. Luas Penampang Tabung (Tube)
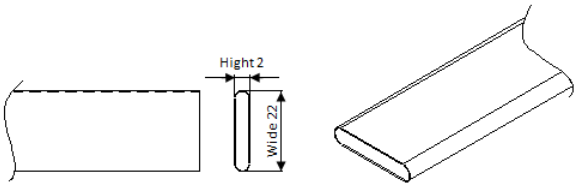

Gambar 4 Tube Dimention Racing

Diketahui Tube Dimention :

Tube Hight $=22 \mathrm{~mm}$

Tube Wide $=2 \mathrm{~mm}$

Maka luas penampang Tube adalah :

$=(($ Tube Hight - Tube Wide $) \times 2)+$

(3.14 x Tube Wide)

$=((22-2) \times 2)+(3,14 \times 2))$

$=46.28 \mathrm{~mm}$

2. Quantity Tube / Row

Diketahui :

Core Wide $\quad=168 \mathrm{~mm}$

Tube Pitch (TP) $\quad=8,5 \mathrm{~mm}$

Fin Hight $\quad=6,5 \mathrm{~mm}$

Maka Quantity Tube / Row adalah :

$=($ Core Wide - Fin Hight $):$ Tube Pitch

(TP)

$=(168-6,5): 8,5$

= 19 Pcs $/$ Row

3. Total Quantity Tube pada Radiator

Diketahui :

Quantity Tube / Row = 19 PcS

Row

$=1 R$ 
Maka Total Quantity Tube pada radiator adalah :

= Quantity tube / row x Row

$=19 \times 1$

$=19$ PCS

4. Core Tube surface area

Diketahui :

Luas Penampang Tube $=46,28 \mathrm{~mm}$

Core Hight $\quad=200$

$\mathrm{mm}$

Quantity tube = 19 PcS

Maka Tube Surface Area pada radiator adalah :

$=$ Luas Penampang Tube $\mathrm{x}$ Core Hight $\mathrm{x}$

Quantity tube : 1000000

$=46,28 \times 200 \times 19: 1000000$

$=0.176 \mathrm{~m}^{2}$

5. Quantity Fin / Row

Diketahui :

Tube $/$ Row $=19 \mathrm{~mm}$

Ketetapan $\quad=1 P c S$

Maka Quantity Fin / Row adalah :

$=$ Tube $/$ Row +1

$=19+1$

= 20 Pcs $/$ Row

6. Total Quantity Fin pada Radiator

Diketahui :

Quantity Fin $/$ Row $=20$ Pcs

Core Hight $\quad=200 \mathrm{~mm}$

$1 / 2$ Fin Pitch (FP) $\quad=1,25 \mathrm{~mm}$

Maka Total Quantity Fin pada radiator adalah :

$=$ Quantity Fin $/$ Row $\mathrm{x}$ Core Hight $:$ Fin

Pitch (FP)

$=20 \times 200: 1,25$

$=3200$ Pcs

7. Luas Corrugated fin length

Diketahui :

Fin Hight

$\mathrm{mm}$

1/2 Fin Pitch (FP) $\quad=1,25$

$\mathrm{mm}$

Fin Thick

$=$

$0,07 \mathrm{~mm}$

Maka Luas Corrugated fin length adalah

$=\left[\left((\text { Fin Hight })^{2}+(\text { Fin Pitch })^{2}\right)^{0^{\prime} 5}\right]-$

Fin Thick

$=\left[\left((6,5)^{2}+(1,25)^{2}\right)^{0^{\prime} 5}\right]-0,07$

$=6,549 \mathrm{~mm}^{2}$

8. Fin Surface Area
Diketahui :

Luas Corrugated fin length $\quad=6,549$

$\mathrm{mm}^{2}$

Core Thick $\quad=23 \mathrm{~mm}$

Maka Fin Surface Area adalah :

$=(2 \mathrm{x}$ Luas Corrugated fin length $\mathrm{x}$

Core Thick)

$=(2 \times 6,549 \times 23)$

$=301,259 \mathrm{~mm}^{2}$

9. Core Fin Surface Area

Diketahui :

Fin Surface Area $\quad=301,259 \mathrm{~mm}^{2}$

Total Quantity Fin $=3200$ Pcs

Maka Core Fin Surface Area pada

radiator adalah :

$=($ Fin Surface Area $x$ Total Quantity

Fin) / 1000000

$=(301,259 \times 3200) / 1000000$

$=0,964 \mathrm{~m}^{2}$

10. Core Total Surface Area (A)

Diketahui :

Core Tube surface area $\quad=0,176$

$m^{2}$

Core Fin Surface Area $\quad=0,964$

$m^{2}$

Maka Core Total Surface Area pada

radiator adalah :

$=0,176+0,964$

$=1,140 \mathrm{~m}^{2}$

11. Perhitungan Laju Perpindahan Kalor

Menyeluruh $(Q)$

Diketahui :

$Q=U . A$ ( $T$ in water $-T$ out air $)$

$$
\begin{aligned}
& U \quad=45 \mathrm{~W} / \mathrm{m}^{2} \mathrm{~K} \\
& \text { A } \quad=1,140 \mathrm{~m}^{2}
\end{aligned}
$$

Di konversi ke dalam satuan Kilo Watt $(K W)$

Dimana $1 W=0,001 \mathrm{KW}$

Maka $Q=2821 \times 0,001=\mathbf{2 , 8 2 1} \boldsymbol{K} \boldsymbol{W}$

12. Delta $T$ Water $(\Delta T)$

Diketahui :

$\Delta T=Q:(\dot{m} \times C p$ water $)$

$\begin{array}{lr}Q & =2821 \mathrm{~W} \\ \dot{m} & =1,16 \mathrm{Kg} / \mathrm{s} \\ \mathrm{Cp} \text { water } & =4206 \mathrm{~J} / \mathrm{Kg} \mathrm{K}\end{array}$


Maka $\Delta T$ adalah :

$=2821:(1,16 \times 4206)$

$=0,58{ }^{\circ} \mathrm{C}$

13. Perhitungan $\mathrm{T}$ out water

Diketahui :

$\mathrm{T}$ out water $=\mathrm{T}$ in water $-\Delta T$

$\mathrm{T}$ in water $=90^{\circ} \mathrm{C}$

$\Delta T \quad=0,58{ }^{\circ} \mathrm{C}$

Maka T out water adalah :

$=90-0,58$

$=89,42{ }^{\circ} \mathrm{C}$

b. Analisa Radiator Original Equiepment Manufacture (OEM)

Ukuran core radiator adalah adalah tinngi $\mathrm{x}$ lebar $\mathrm{x}$ tebal $=\mathrm{H} \times \mathrm{W} \times \mathrm{T} \mathrm{mm}$. Untuk jenis yang digunakan adalah $(198 \times 128 \times 24) \mathrm{mm}$.
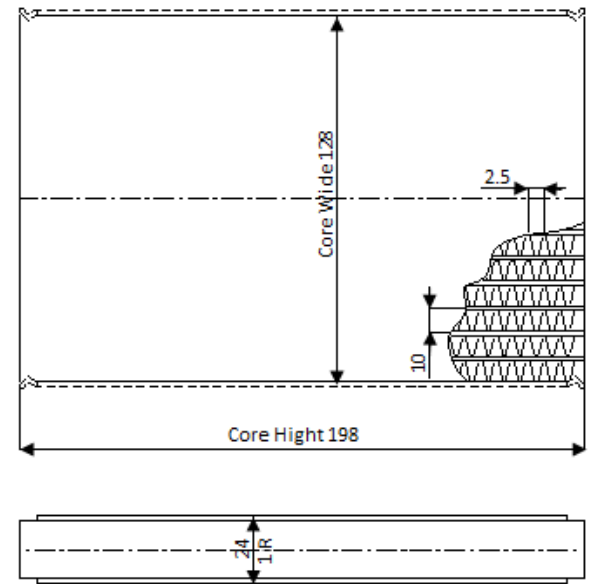

Gambar 5 Dimensi Core OEM

1. Luas Penampang Tabung (Tube)
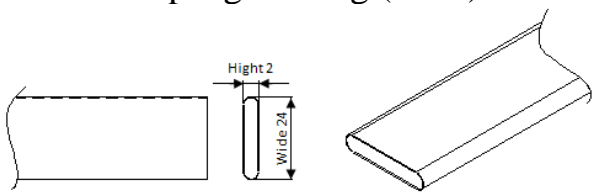

Gambar 6 Tube Dimention OEM

Diketahui Tube Dimention :

Tube Hight $=24 \mathrm{~mm}$

Tube Wide $=2 \mathrm{~mm}$

Maka luas penampang Tube adalah :

$=(($ Tube Hight - Tube Wide $) \times 2)+$

(3,14 x Tube Wide)

$=((24-2) \times 2)+(3,14 \times 2))$

$=\mathbf{5 0 , 2 8} \mathbf{~ m m}$

2. Quantity Tube / Row

Diketahui :

Core Wide

Tube Pitch (TP)

Fin Hight

$=128 \mathrm{~mm}$

$=10 \mathrm{~mm}$

$=8 \mathrm{~mm}$

Maka Quantity Tube / Row adalah :
$=($ Core Wide - Fin Hight $):$ Tube Pitch

(TP)

$=(128-8): 10$

= 12 Pcs $/$ Row

3. Total Quantity Tube pada Radiator

Diketahui :

Quantity Tube $/$ Row $=12$ PcS

Row $\quad=1 R$

Maka Total Quantity Tube pada radiator adalah :

= Quantity tube / row $\mathrm{x}$ Row

$=12 \times 1$

$=12$ PcS

4. Core Tube surface area

Diketahui :

Luas Penampang Tube $=50,28 \mathrm{~mm}$

Core Hight $\quad=198$

$\mathrm{mm}$

Quantity tube $=12$ Pcs

Maka Tube Surface Area pada radiator

adalah :

= Luas Penampang Tube $\mathrm{x}$ Core Hight $\mathrm{x}$

Quantity tube : 1000000

$=50,28 \times 198 \times 12: 1000000$

$=0,119 \mathrm{~m}^{2}$

5. Quantity Fin / Row

Diketahui :

Tube $/$ Row $=12 \mathrm{~mm}$

Ketetapan $\quad=1 P C S$

Maka Quantity Fin / Row adalah :

$=$ Tube $/$ Row +1

$=12+1$

= 13 Pcs $/$ Row

6. Total Quantity Fin pada Radiator

Diketahui :

Quantity Fin / Row $=13$ Pcs

Core Hight $\quad=198 \mathrm{~mm}$

1/2 Fin Pitch (FP) $\quad=1,25 \mathrm{~mm}$

Maka Total Quantity Fin pada radiator adalah :

$=$ Quantity Fin / Row x Core Hight : Fin

Pitch (FP)

$=13 \times 198: 1,25$

$=2059$ Pcs

7. Luas Corrugated fin length

Diketahui :

Fin Hight $\quad=8 \mathrm{~mm}$

$1 / 2$ Fin Pitch $(\mathrm{FP}) \quad=1,25 \mathrm{~mm}$

Fin Thick $\quad=0,07 \mathrm{~mm}$ 
Maka Luas Corrugated fin length adalah

$=\left[\left((\text { Fin Hight })^{2}+(\text { Fin Pitch })^{2}\right)^{0^{\prime} 5}\right]-$

Fin Thick

$=\left[\left((8)^{2}+(1,25)^{2}\right)^{0,5}\right]-0,07$

$=8,027 \mathrm{~mm}^{2}$

8. Fin Surface Area

Diketahui :

Luas Corrugated fin length $\quad=8,027$

$\mathrm{mm}^{2}$

Core Thick

$24 \mathrm{~mm}$

Maka Fin Surface Area adalah :

$=(2 \mathrm{x}$ Luas Corrugated fin length $\mathrm{x}$

Core Thick)

$=(2 \times 8,027 \times 24)$

$=385,299 \mathrm{~mm}^{2}$

9. Core Fin Surface Area

Diketahui :

Fin Surface Area $\quad=385,299 \mathrm{~mm}^{2}$

Total Quantity Fin $=2059$ PcS

Maka Core Fin Surface Area pada

radiator adalah :

$=($ Fin Surface Area $\mathrm{x}$ Total Quantity

Fin) / 1000000

$=(385,299 \times 2059) / 1000000$

$=0,793 \mathrm{~m}^{2}$

10. Core Total Surface Area (A)

Diketahui :

Core Tube surface area $\quad=0,119$

$m^{2}$

Core Fin Surface Area $\quad=0,793$

$m^{2}$

Maka Core Total Surface Area pada

radiator adalah :

$=0,119+0,793$

$=0,913 \mathrm{~m}^{2}$

11. Perhitungan Laju Perpindahan Kalor

Menyeluruh $(Q)$

Diketahui :

$Q=\mathrm{U} . \mathrm{A}$ ( $\mathrm{T}$ in water $-\mathrm{T}$ out air $)$
$\mathrm{U} \quad=45 \mathrm{~W} / \mathrm{m}^{2} \mathrm{~K}$
A $\quad=1,140 \mathrm{~m}^{2}$

$\mathrm{T}$ in water $=90^{\circ} \mathrm{C}$

$\mathrm{T}$ out air $\quad=35^{\circ} \mathrm{C}$

Maka laju Perpindahan Kalor

Menyeluruh $(Q)$ adalah :

$=45 \times 0,913 \times(90-35)$

$=2259 \mathrm{~W}$

Di konversi ke dalam satuan Kilo Watt $(K W)$

Dimana $1 W=0,001 K W$
Jadi $Q=2821 \times 0,001=\mathbf{2 , 2 5 9} \mathbf{K W}$

12. Delta $T$ Water $(\Delta T)$

Diketahui :

$\Delta \mathrm{T}=Q:(\dot{m} \times C p$ water $)$

$$
\begin{array}{ll}
Q & =2259 \mathrm{~W} \\
\dot{m} & =1,16 \mathrm{Kg} / \mathrm{s} \\
\mathrm{Cp} \text { water }=4206 \mathrm{~J} / \mathrm{Kg} \mathrm{K} & \\
\text { Maka } \Delta T \text { adalah : } \\
=2259:(1,16 \times \text { 4206) } \\
=\mathbf{0 , 4 6}{ }^{\circ} \mathbf{C}
\end{array}
$$

13. Perhitungan $\mathrm{T}$ out water

Diketahui :

$\mathrm{T}$ out water $=\mathrm{T}$ in water $-\Delta T$

$\mathrm{T}$ in water $=90{ }^{\circ} \mathrm{C}$

$\Delta T=0,46{ }^{\circ} \mathrm{C}$

Maka $\mathrm{T}$ out water adalah :

$=90-0,46$

$=89,54{ }^{\circ} \mathrm{C}$

\section{a. Data Prosedur Pengujian}

Prosedur pengujian yang dilakukan pada radiator motor Racing dan OEM (Original Eqiuepment Manufacture) meliputi beberapa parameter sesuai pada Tabel 5 di bawah.

Tabel 5 Data Prosedur Pengujian

\begin{tabular}{|c|l|c|c|}
\hline \multirow{2}{*}{ No } & Parameters & $\begin{array}{c}\text { Radiator } \\
\text { OEM }\end{array}$ & $\begin{array}{c}\text { Radiator } \\
\text { Racing }\end{array}$ \\
\cline { 2 - 4 } & $\begin{array}{c}\text { TSI } \\
\text { (Three } \\
\text { Star } \\
\text { Indonesia) }\end{array}$ & PT AAI \\
\hline & $\begin{array}{l}\text { Overall } \\
\text { Heat } \\
\text { Transfer } \\
\left(\text { W/ } \mathrm{m}^{2} \mathrm{~K}\right)\end{array}$ & 45 & 45 \\
\hline 2 & $\begin{array}{l}\text { Mass Flow } \\
\text { Rate }(\text { Kg } / \mathrm{s})\end{array}$ & 1.16 & 1.16 \\
\hline 3 & $\begin{array}{l}\text { Specific } \\
\text { Heat } \\
\text { Capacity } \\
(\text { J } / \text { Kg } \mathrm{K})\end{array}$ & 4206 & 4206 \\
\hline 4 & $\begin{array}{l}\text { Input } \\
\text { Temperature } \\
\text { Water }\left({ }^{\circ} \mathrm{C}\right)\end{array}$ & 90 & 90 \\
\hline 5 & \begin{tabular}{l} 
Output \\
\hline
\end{tabular}
\end{tabular}




\begin{tabular}{|l|l|l|}
\hline $\begin{array}{l}\text { Temperature } \\
\text { Air }\left({ }^{\circ} \mathrm{C}\right)\end{array}$ & & \\
\hline
\end{tabular}

\section{b. Perbandingan Radiator Original Equiepment Manufacture (OEM) terhadap Racing}

Tabel berikut ini Tabel berikut ini yang dapat kita lihat pada Tabel 6 dan Gambar 7 yang menyatakan hasil perbandingan radiator $O E M$ dan Racing :

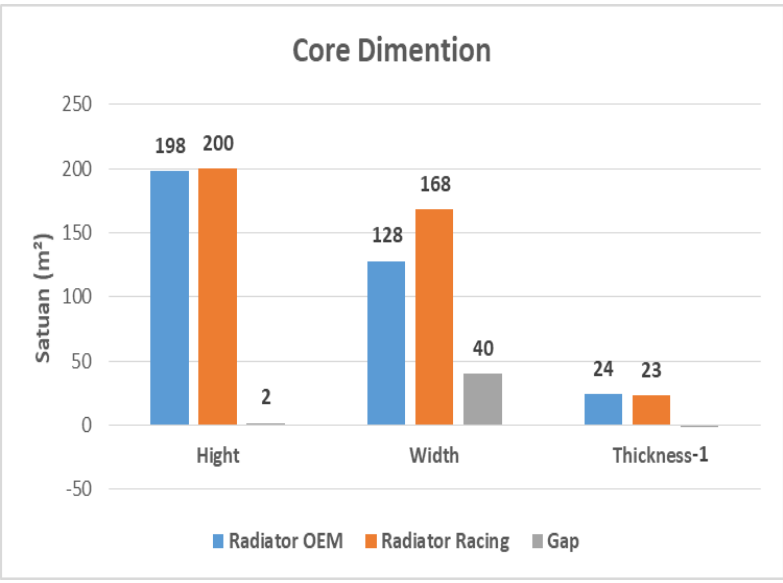

Gambar 7 Perbandingan Core Dimention

Tabel 6 Core Specification

\begin{tabular}{|c|c|c|}
\hline Description & $\begin{array}{c}\text { Radiator } \\
\text { OEM }\end{array}$ & $\begin{array}{c}\text { Radiator } \\
\text { Racing }\end{array}$ \\
\hline Make & $\begin{array}{c}\text { TSI (Three } \\
\text { Star Indonesia) }\end{array}$ & PT AAI \\
\hline $\begin{array}{c}\text { Core }(H \times W \times \\
\text { THK) }\end{array}$ & $198 \times 128 \times 24$ & $200 \times 168 \times 23$ \\
\hline Tube/Row $\times$ Row & $12 \times 1$ & $19 \times 1$ \\
\hline $\begin{array}{c}\text { Size of Tube }(W x \\
\text { H) }\end{array}$ & $24 \times 2,0$ & $22 \times 2,0$ \\
\hline Fin Thickness & 0,07 & 0,07 \\
\hline Fin Hight & 8,0 & 6,5 \\
\hline $\begin{array}{c}\text { Tube Pitch } \times \text { Fin } \\
\text { Pitch }\end{array}$ & $10 \times 2,5$ & $8.5 \times 2,5$ \\
\hline Block Material & Alumunium & Alumunium \\
\hline
\end{tabular}

Dari hasil perhitungan luas area core antara radiator $O E M$ dan Racing terdapat Gap pada Heat Area Tube 0,056 $\mathrm{m}^{2}$, Heat Area Fin $1,171 \mathrm{~m}^{2}$, dan secara Total Heat Area $(A)$
0,227 $\mathrm{m}^{2}$ dapat dilihat pada Tabel 7 dan Gambar 8 di bawah ini.

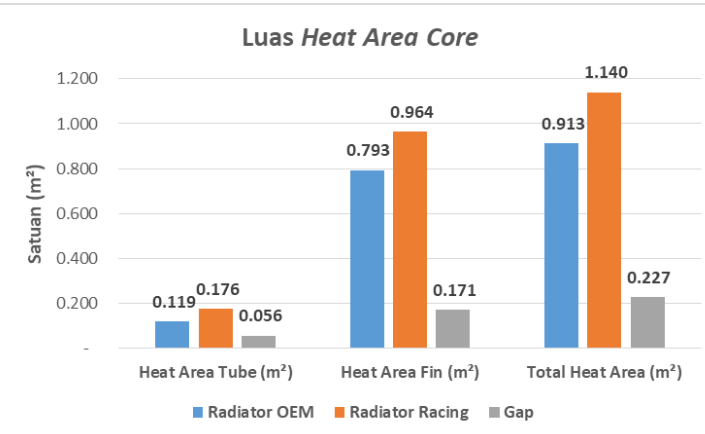

Gambar 8 Perbandingan Luas Area Core

Tabel 7 Perbandingan Luas Area Core

\begin{tabular}{|c|c|c|c|}
\hline Description & $\begin{array}{c}\text { Radiator } \\
\text { OEM }\end{array}$ & $\begin{array}{c}\text { Radiator } \\
\text { Racing }\end{array}$ & Gap \\
\hline $\begin{array}{c}\text { Heat Area } \\
\text { Tube }\left(m^{2}\right)\end{array}$ & 0,119 & 0,176 & 0,056 \\
\hline $\begin{array}{c}\text { Heat Area } \\
\text { Fin }\left(m^{2}\right)\end{array}$ & 0,793 & 0,964 & 0,171 \\
\hline $\begin{array}{c}\text { Total Heat } \\
\text { Area }\left(m^{2}\right)\end{array}$ & 0,913 & 1,140 & 0,227 \\
\hline
\end{tabular}

Dari hasil perhitungan laju perpindahan kalor menyeluruh $(Q)$ yang terjadi pada radiator OEM dan Racing maka dapat kita bandingkan dimana $(Q)$ yang terjadi pada radiator OEM sebesar 2259 Watt dan $(Q)$ yang terjadi pada radiator Racing sebesar 2821 Watt dengan Gap 562 Watt, bisa dilihat pada Tabel 4.3 dan Gambar 9.

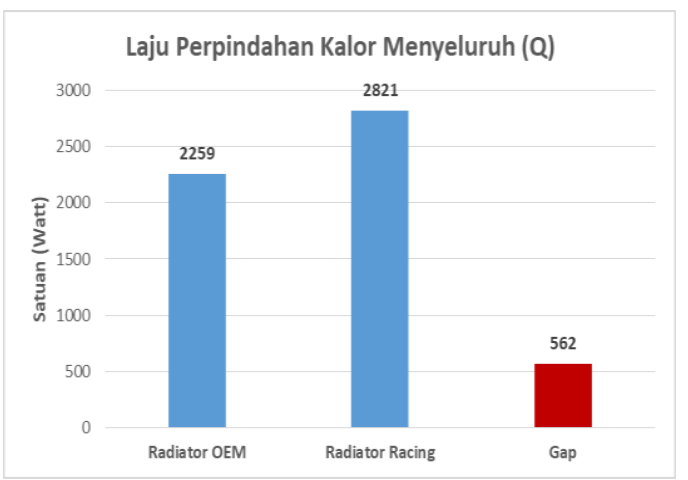

Gambar 9 Perbandingan Laju Perpindahan Kalor Menyeluruh 
Tabel 8 Perbandingan Laju Perpindahan Kalor Menyeluruh

\begin{tabular}{|c|c|c|c|}
\hline Description & $\begin{array}{c}\text { Radiator } \\
\text { OEM }\end{array}$ & $\begin{array}{c}\text { Radiator } \\
\text { Racing }\end{array}$ & Gap \\
\hline$Q($ Watt $)$ & 2259 & 2821 & 562 \\
\hline
\end{tabular}

Dari hasil perhitungan $\Delta \mathrm{T}$ Water suhu yang dapat diturunkan pada radiator $O E M$ sebesar $0,46{ }^{\circ} \mathrm{C}$ maka $T$ Out Water $89,54{ }^{\circ} \mathrm{C}$ sedangkan pada radiator Racing suhu yang dapat diturunkan sebesar $0,58{ }^{\circ} \mathrm{C}$ maka $T$ Out Water $89,42{ }^{\circ} \mathrm{C}$ dengan Gap $0,12{ }^{\circ} \mathrm{C}$, dapat dilihat pada Tabel 7 dan Gambar 9.

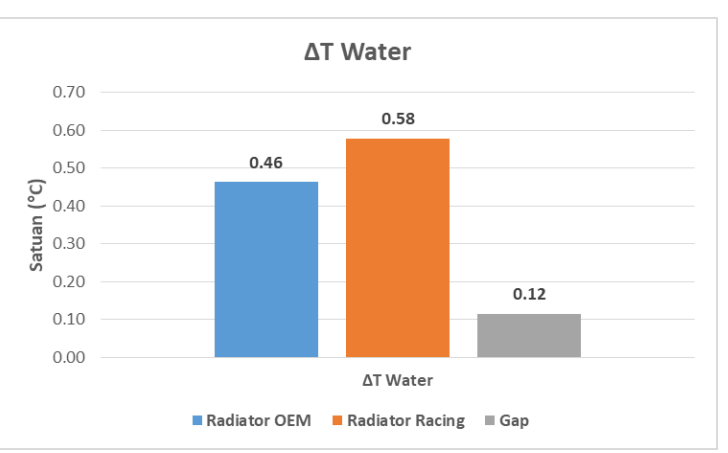

Gambar 9 Perbandingan

$\Delta T, T$ in, \& $T$ out Water

Tabel 9 Perbandingan $\Delta T, T$ in, \& $T$ out Water

\begin{tabular}{|l|c|c|c|}
\hline \multicolumn{1}{|c|}{ Description } & $\begin{array}{c}\text { Radiator } \\
\text { OEM }\end{array}$ & $\begin{array}{c}\text { Radiator } \\
\text { Racing }\end{array}$ & Gap \\
\hline$\Delta$ T Water $\left({ }^{\circ} \mathrm{C}\right)$ & 0,46 & 0,58 & 0,12 \\
\hline T In Water $\left({ }^{\circ} \mathrm{C}\right)$ & 90,00 & 90,00 & - \\
\hline $\begin{array}{l}\text { T Out Water } \\
\left({ }^{\circ} \mathrm{C}\right)\end{array}$ & 89,54 & 89,42 & $-0,12$ \\
\hline
\end{tabular}

\section{Kesimpulan}

Berdasarkan hasil analisis yang telah dilakukan dapat kita simpulkan sebagai berikut :

1. Berdasarkan design heat exchanger (Radiator) yang terpenting adalah luas dari pada sarang core tingi $\mathrm{x}$ lebar $\mathrm{x}$ tebal $=(\mathrm{H} \mathrm{x} \mathrm{W} \mathrm{x} \mathrm{T)} \mathrm{mm}$ :

a. Pada radiator Racing dengan dimensi core $(200 \times 168 \times 23)$ $\mathrm{mm}$ dengan total luas permukaan core (A) $1,140 \mathrm{~m}^{2}$ maka laju perpindahan kalor $(Q)$ menyeluruh (konveksi dan konduksi) yang terjadi sebesar 2821 Watt.

b. Pada radiator Original Equiepment Manufacture (OEM) dengan dimensi core $(198 \times 128 \times$ 24) $\mathrm{mm}$ dengan total luas

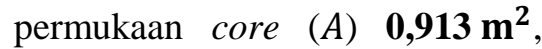
maka laju perpindahan kalor $(Q)$ menyeluruh (konveksi dan konduksi) yang terjadi sebesar 2259 Watt dengan Gap (selisih) 562 Watt.

2. Berdasarkan penuruna suhu water $(\Delta \mathrm{T}$ Water) yang terjadi seperti di bawah ini :

a. Penuruna suhu water $(\Delta \mathrm{T}$ Water $)$ yang terjadi pada radiator Racing sebesar $0,58^{\circ} \mathrm{C}$.

b. Penurunan suhu water $(\Delta \mathrm{T}$ Water $)$ pada radiator Original Equiepment Manufacture (OEM) sebesar $0,46^{\circ} \mathrm{C}$, maka Gap yang diperoleh dari perbandingan adalah $0,12^{\circ} \mathrm{C}$.

Daftar Notasi

\begin{tabular}{|c|l|c|}
\hline Simbol & \multicolumn{1}{|c|}{ Ketrangan } & Satuan \\
\hline$A$ & Luas penampang & $\mathrm{m}^{2}$ \\
\hline$C$ & Panas spesifik & $\mathrm{kj} / \mathrm{kg} . \mathrm{K}$ \\
\hline$C p$ & $\begin{array}{l}\text { Panas spesifik pada tekanan } \\
\text { konstan }\end{array}$ & $\mathrm{kj} / \mathrm{kg} \cdot \mathrm{K}$ \\
\hline$C v$ & $\begin{array}{l}\text { Panas spesifik pada volume } \\
\text { konstan }\end{array}$ & $\mathrm{kj} / \mathrm{kg} \cdot \mathrm{K}$ \\
\hline$d$ & Diameter & $\mathrm{mm}$ \\
\hline$D$ & kedalaman atau diameter & $\mathrm{mm}$ \\
\hline$g$ & Percepatan gravitasi & $\mathrm{m} / \mathrm{s}^{2}$ \\
\hline$h$ & Koefesien perpindahan kalor & $\mathrm{W} / \mathrm{m}^{2} .{ }^{\circ} \mathrm{C}$ \\
\hline $\bar{h}$ & $\begin{array}{l}\text { Koefesien perpindahan kalor } \\
\text { rata-rata }\end{array}$ & $\mathrm{W} / \mathrm{m}^{2} .{ }^{\circ} \mathrm{C}$ \\
\hline$H$ & Tinggi & $\mathrm{mm}$ \\
\hline$W$ & Panjang & $\mathrm{mm}$ \\
\hline$T$ & Tebal & $\mathrm{mm}$ \\
\hline$m$ & Masa & $\mathrm{kg}$ \\
\hline$v$ & Volume & \\
\hline
\end{tabular}




\begin{tabular}{|c|l|c|}
\hline$\rho$ & Masa jenis & $\mathrm{kg} / \mathrm{l}$ \\
\hline$\dot{M}$ & Laju aliran masa & $\mathrm{kg} / \mathrm{s}$ \\
\hline$Q$ & laju perpindahan kalor & $W$ \\
\hline$T$ in & Suhu water & ${ }^{0} \mathrm{C}$ \\
\hline$T$ out & Suhu air & ${ }^{0} \mathrm{C}$ \\
\hline$u$ & Kecepatan & $\mathrm{m} / \mathrm{s}$ \\
\hline$U$ & $\begin{array}{l}\text { Koefesien perpindahan kalor } \\
\text { total }\end{array}$ & $\mathrm{W} / \mathrm{m}^{2} . \mathrm{K}$ \\
\hline$\Delta T$ & Perbedaan temperature & ${ }^{0} \mathrm{C}$ \\
\hline Row & Tube per Baris & $R$ \\
\hline
\end{tabular}

\section{Daftar Pustaka}

Cengel Yunus A. 2007. Heat Transfer A Practical Approach. Mcgraw-Hill.

Daryanto. 1992. Teknik Servis Mobil. Jakarta : Rireka Cipta.

Daryanto. 2009. Teknik Otomotif Edisi 1. Jakarta : Bumi Aksara.

David Fraim Simamora, Frans P. Sappu, Tertius V.Y. Ulaan. Analisis Efektivitas

Radiator pada Mesin Toyota Kijang Tipe 5

$K$. Jurnal Teknik Mesin, Volume 4 Nomor

2. Universitas Sam Ratulangi.

Eko Surjadi. Pengaruh Penggunaan Radiator pada Sistem Pendingin Motor Diesel Stasioner Satu Silinder Terhadap Laju Kenaikan Suhu Air Pendingin. Jurnal Teknik Mesin, Volume 1 Nomor 3 Juni Tahun 2016. ISSN : 2442-7918.

Heroe Poernomo. Pembuatan Alat Monitoringmesin Penukar Panas (Heat Exchanger) untuk Menganalisis Unjuk Kerja dan Karakteristiknya. Jurnal Teknik Permesinan Kapal, Volume 10 Nomor 3 Oktober 2013.

Holman.J.P. 1984. Perpindahan Kalor Edisi 5. Jakarta : Erlangga.

Koestor, Raldi Artono. 2002. Perpindahan Kalor. Jakarta : Salemba Teknik.

Luki Apriliasari, Djatmiko Ichsani. Desain Compact Heat Exchanger Tipe Fin and Tube Sebagai Alat Pendingin Motor pada Boiler Feed Pump (Studi Kasus pada Sebuah Perusahaan Pembangkit Tenaga Listrik). Jurnal Teknik Mesin, Volume 2 Nomor 2 Tahun 2013. ISSN: 2337-3539.
Made Ricki Murti. Laju Pembuangan Panas pada Radiator dengan Fluida Campuran 80\% Air dan 20\% RC pada RPM Konstan. Jurnal Teknik Mesin, Volume 2 Nomor 1 Juni 2008.

Pieter W. Tetelepta. Analisis Pengaruh Beban Panas (Q) Terhadap Karakteristik Perpindahan Panas Konveksi Natural Pelat Datar. Jurnal Teknik Mesin, Volume 5 Nomor 2 Tahun 2010. 803 - 807.

Rohman T, Hary Sutjahjono, Digdo Listyadi. Penambahan dan Variasi Dimensi Sirip Aluminium pada Tube Terhadap Laju dan Efektivitas Perpindahan Panas dalam Heat Exchanger Tipe Shell and Tube. Jurnal Teknik Mesin, Volume 6 Nomor 2, November 2013.

Taufiq Hidayat. Modifikasi Air Scoop dan Jarak Radiator Terhadap Konsumsi Bahan Bakar Bensin. Jurnal Sainstech, Volume 1 Nomor 3 Tahun 2015. ISSN : 2355-5009.

Wikipedia - Sistem Pendinginan - Minggu, 4 Mei 2017 -

https://id.wikipedia.org/wiki/Sistem_pendin ginan.

Wikipedia - Mass Flow Rate - Sabtu, 28 Oktober 2017 -

https://en.wikipedia.org/wiki/Mass_flow_ra te.

Yopi Handoyo, Ahsan. Analisis Kinerja Alat Penukar Kalor Jenis Shell and Tube

Pendingin Aliran Air pada PLTA Jatiluhur. Jurnal Teknik Mesin, Volume 5 Nomor 1, Oktober 2012.

Zuhdi Ma'sum, Mada Arsana, Fathurrahman Malik, DKK. Analisis Perpindahan Panas gengan Konveksi Bebas dan Radiasi pada Penukar Panas Jenis Pipa dan Kawat. Jurnal Teknik Kimia, Volume 7 Nomor 1 September 2012. 